\title{
Islanding Operation of Hybrid Microgrids with High Integration of Wind Driven Cage Induction Generators
}

\author{
Mir Nahidul Ambia, Ahmed Al-Durra*, Cedric Caruana, and S. M. Muyeen \\ Electrical Engineering Department, The Petroleum Institute, P.O. Box 2533, Abu Dhabi, UAE
}

\begin{abstract}
This paper proposes two control strategies for the islanding operation of hybrid microgrid with a high penetration of wind driven cage induction generators. The control strategies combine approaches traditionally applied to self-excited cage induction generators with recent approaches for microgrid's islanding operation. The proposed control strategies aim to facilitate the higher integration of cage induction generators in microgrids. The first strategy is based on direct frequency and reactive power control while the second one uses an artificial grid to regulate the voltage amplitude and frequency. The proposed schemes are tested in PSCAD/EMTDC using a real wind speed pattern measured at Hokkaido Island of Japan. Simulation results show the successful operation of both schemes. The implementation simplicity and costeffectiveness of both schemes are explained as well.
\end{abstract}

Index Terms: Battery energy storage system, frequency loop, induction generator, islanding, micro-grid, resynchronization.

\section{INTRODUCTION}

Significant effort is being directed nowadays for increasing the share of alternative energy in the energy mix. The increase in the presence of Distributed Generation (DG) and the presence of multiple DGs in proximity to one another has brought about the concept of the microgrid [1,2]. Local DGs, loads and smaller scale energy storage systems can be interconnected to form a microgrid [3]. The physical proximity of the generation and the loads allow technical benefits and control flexibility that provides opportunities for increasing the efficiency, enhancing the reliability and improving the power quality of power systems [4]. Microgrids also have the potential to alleviate the present high levels of power flows in critical grid sections [5]. In such way, distributed energy resources, rather than burdening the system, add benefits to the power system [6]. The microgrid can operate in both grid connected and islanded modes of operation [7]. Islanded operation may be intentional or forced. Islanding operation capability allows the microgrids to continue supplying local loads even when the utility grid fails. This is in contrast to distributed generators operating on the utility grid that are required to disconnect once islanded operation is detected [8]. Sectionalizing switches can be used to isolate the microgrid for islanded operation [5]. The arrangement also allows intentional disconnection to reduce the dependency on the grid and possibly exploit more alternative energy.

The balance between the supply and demand is one of the most important requirements of microgrid management. Any imbalance in power can lead to significant frequency deviations due to the low inertia present in the system [3]. The frequency and also the voltage magnitude of islanded microgrids have to be controlled [3,5]. The inclusion of energy storage elements as part of the microgrid and the use of load shedding techniques are considered as effective solutions to allow high dynamic control and hence avoid large frequency and voltage excursions $[3,9,10]$.

The different operational philosophy of microgrids as compared to traditional power networks brings about the need of adequate control strategies. Tiered control strategies are typically used. Primary, secondary and tertiary control algorithms are proposed in [6]. The primary control regulates the frequency and the voltage to ensure stable operation. This level of control is crucial and needs to be operated in a reliable way. The aim of the secondary control is to minimize the frequency and voltage deviations and drive the average deviation to zero. Tertiary control achieves the optimal distribution of the load between the energy sources for more economic operation. The secondary and the tertiary controls can be combined in the same algorithm [10,11]. Due to the distributed physical location of the elements of the microgrid, the control schemes for the different control tiers can be classified into two main groups as regards the use of control wire interconnections [9]. The first group requires critical interconnection lines between the elements. Apart from the cost, the dependence on the control lines limits the system reliability and expandability. The second group bases the control only on local measurements. This leads to a higher reliability and more flexibility in the location of the elements.

A number of distributed generators are interfaced to the grid through a power electronic inverter. Two forms of control can be used to operate the inverter - PQ control and VSI control $[5,10,12]$. In PQ control, the inverter is set to supply/absorb set active and reactive power references. Typically the PQ inverter is set to deliver all the active power available at its 
input and to provide a fixed reactive power, else participate in the voltage regulation [10]. Sources that require a maximum power tracker algorithm are interfaced through a PQ controlled inverter [12]. In VSI control, the inverter is controlled to supply the load with given values of voltage and frequency. The real and reactive power outputs will then be defined automatically [5].

Primary control can be achieved through a central controller that needs high bandwidth communication with the microgrid elements. Flexible solutions require that each inverter operates only on the basis of local measurements and hence independent of the actual configuration of the microgrid and the other generators [5]. Isochronous control can be used where the frequency is controlled to a constant value but this can be applied to only one unit [5]. Voltage and frequency droop control is a common solution as it automatically allows for power sharing between parallel units [5, 10]. Droop control presents the advantages of low cost, simple expansion of the system, increased redundancy and simplified supervisory control [4]. Implementation of the droop control should consider the line impedance due to the different characteristics of high and low voltage lines [6]. The degraded frequency and voltage regulation due to the droop control is generally considered acceptable if the frequency and amplitude deviations remain within predefined limits [6, 9]. In microgrid islanded operation, one or more inverters will be operated in VSI mode to provide a reference for the voltage amplitude and frequency hence allowing the other inverters in PQ mode to continue operating [10]. Despite the voltage and frequency regulation, the microgrid voltage will not be in phase with the utility grid voltage. To avoid hard transitions when reconnecting to the grid, the microgrid voltage can be synchronized to the grid voltage before reconnection [8].

If the droop controlled frequency stabilizes to a value different from the nominal one, storage devices would keep on injecting or absorbing active power [10]. In order to limit the required capacity of the energy storage elements, correcting permanent frequency deviations during islanded operations should be one of the key objectives of the control strategy [10]. This is precisely the aim of the secondary control, which will adjust the operating point of the sources accordingly. Secondary control can be performed locally or through a central controller. Central secondary control can be done on a low frequency basis to restrict the bandwidth requirements of the communication system [11]. The droop characteristic can be implemented is such way that it has the ability to shift the settings in response to deviations from the nominal frequency thus avoiding the need of the central controller [13].

Microgrids facilitate the integration of several kinds of renewable energy sources [5]. Wind energy is no exception. The growth rate of wind energy has increased significantly because of available wind resources and rapid technical development of wind farms [14, 15]. Several control strategies have been published for the integration of wind turbines to the grid. Recently double fed induction generators (DFIG) and permanent magnet synchronous generators (PMSM) have become popular. They offer advantages of variable speed operation and control of the wind energy conversion. However a large number of cage induction generators are still used for wind energy conversion. The cage induction machine is attractive for wind energy generation due to its low cost, robustness, absence of moving contacts and ease of maintenance $[16,17,18,19,20]$. It is also widely used in industry. Various solutions for the self-excited induction generators have been published in the literature. Reactive power consumption and poor voltage regulation under varying speed can be seen as the major drawbacks of induction generators [17]. Advance in power electronic converters led to the development of low cost schemes for the regulation of the cage induction generator output voltage and frequency [20]. Most of the research paper with ac micro-grid system has rarely considered induction generators due to its reactive power consumption and poor voltage regulation. In [21] a back to back converter is used in the microgrid system with dc sources as major source. A real power controlled is designed for islanding operation in [22] for ac dc microgrid system.

This paper proposes two control strategies for the islanding operation of ac-dc hybrid microgrids with a high penetration of wind driven cage induction generators, where the previous research real and reactive power control [21, 22] is modified. The first strategy is based on direct frequency and reactive power control while the second one uses an artificial grid to regulate the voltage amplitude and frequency. The additional two control loops of frequency correction and resynchronization used in direct frequency and reactive power control is simple and unique. On the other hand, the additional grid control strategy is more robust in terms of islanding operation and grid resynchronization. In both cases, induction generator is used as ac source along with smoothing operation of fluctuated wind output power by battery energy storage system, which makes the microgrid system more complex. Two comparative solutions for widely used induction generator (IG) in industries for microgrid system makes the manuscript unique. The performance of the proposed techniques is first tested in simulations using a constant wind speed to focus on the islanding and grid reconnection transients. Results are then shown for the two schemes working in a realistic scenario where the wind turbines are driven by actual wind speed data. Simulations are done in PSCAD/EMTDC.

\section{ISLANDED OPERATION OF WIND DRIVEN CAGE INDUCTION GENERATOR}

Cage induction generators have been widely used as wind generators due to their superior characteristics [18]. Various literatures have examined the performance of the cage induction generator operating as a self-excited generator, which corresponds to operation in islanded mode. It is generally known that a capacitor bank is required at the terminals of a generator in such mode [16]. The size of the capacitor bank determines the no load terminal voltage, which is limited by the saturation of the magnetic circuit of the machine [23]. There is a strong connection between the 


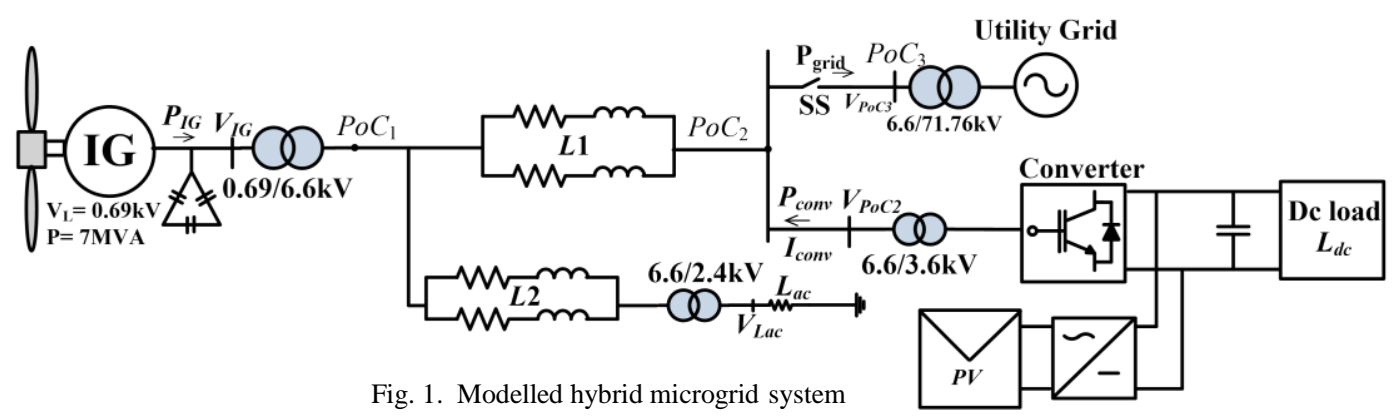

frequency and voltage in the induction generator [24]. In islanded operation, the generator sets both voltage and frequency by itself [24]. When the generator loading increases, the reactive power supplied to the generator has to increase to keep a constant terminal voltage. Various solutions are published for varying the reactive power of the self-excited generator to regulate the terminal voltage. However active and reactive power control yields a better voltage and frequency regulation to load variations than reactive power alone [16]. Reference [20] proposes the use of a reduced rating (compared to generator) shunt connected inverter with a battery bank on the dc side to regulate the voltage amplitude and frequency of a wind driven self-excited induction generator. The active power absorbed or injected by the inverter is driven by the active power the inverter cannot absorb, say due to fully charged battery or when the rated value is exceeded. An insight of the variation of the reactive power requirement at different operating conditions is given in [23].

\section{MODELED SYSTEM}

\section{A. Wind Turbine Modeling}

The wind turbine extracted power $\left(P_{W}\right)$ can be expressed as follows [25]:

$$
P_{W}=\frac{1}{2} \rho \pi R^{2} C_{p}(\lambda, \beta) V_{w}{ }^{3}
$$

where $\rho$ is the air density, $R$ is the radius of the turbine, $V_{w}$ is the wind speed, $C_{P}(\lambda, \beta)$ is the power coefficient given by (2), where the tip speed ratio $\lambda$ is given by (3) in terms of the turbine rotational speed $\omega$.

$$
\begin{gathered}
C_{p}(\lambda . \beta)=\frac{1}{2}\left(\lambda-0.022 \beta^{2}-5.6\right) e^{-0.17 \lambda} \\
\lambda=\frac{\omega R}{V_{w}}
\end{gathered}
$$

The wind turbine and the wind generator are modeled as a one mass lumped model with a constant inertia [19]. The step up gearbox is assumed to be lossless and is represented by a simple gain [20]. The wind farm is aggregated into one large generator.

\section{B. AC-DC Hybrid Micro-grid}

The one line diagram of the modeled ac-dc hybrid microgrid system is shown in Fig. 1. The hybrid microgrid consists of an ac- and dc- sub grids interfaced by a power electronic converter. The four quadrant operating interface converter can act as an inverter or rectifier [26]. The hybrid microgrid increases the system efficiency by eliminating multiple DC$\mathrm{AC}-\mathrm{DC}$ and $\mathrm{AC}-\mathrm{DC}-\mathrm{AC}$ conversions as it directly integrates dc/ac sources and loads to dc/ac busses respectively [27]. Various de loads such as light emitting diode lights and electric vehicles are becoming popular nowadays [27].

A 7MVA, wind driven, cage induction generator is connected to the ac bus. A capacitor bank is connected at the generator terminals. The size of the capacitor bank is selected to maintain unity power factor at rated wind speed in utility grid connected mode. The wind turbine is pitch controlled to regulate the extracted power to $1.0 \mathrm{pu}$ at wind speeds above rated. The output voltage of the cage induction generator is stepped up to the ac bus voltage of $6.6 \mathrm{kV}$. The ac bus is interconnected to the utility grid through a medium length line $\left(L_{1}\right)$ and a sectionalizing switch $(S S)$. A three phase, $2.21 \mathrm{MW}$, $2.4 \mathrm{kV}$, fixed impedance resistive load $\left(L_{a c}\right)$ is connected to the ac bus at Point of Coupling $\left(P o C_{1}\right)$ through a short line $\left(L_{2}\right)$. A phase shift of $\pi / 6$ rads is assumed for all transformers. A photovoltaic (PV) system and a fixed resistance 2.13MW load $\left(L_{d c}\right)$ are connected to the dc bus. A constant solar irradiation is assumed such that the PV system delivers $0.5 \mathrm{MW}$ to the dc bus. The dc bus voltage is set at $6.6 \mathrm{kV}$. The dc loads can be connected directly or through appropriate dc-dc converters [28]. The dc sub grid is interconnected to the ac sub grid at $\mathrm{PoC}_{2}$ through a standard two level converter. During grid connected operation, the converter is operated in PQ mode, where the $\mathrm{P}$ reference is obtained from a central controller such that active power balance is maintained on the dc side. The $\mathrm{Q}$ reference is obtained through a local voltage magnitude control loop, regulating the voltage level at $P_{o} C_{2}$. Standard cascaded vector control is used for the converter, as shown in Fig. 2. The control is done in the dq frame synchronized to the voltage sampled at $P o C_{2}$. The cage induction generator's parameters are shown in Table 1 in the Appendix. Microgrid parameters and the assumed operating point are shown in Table 2.

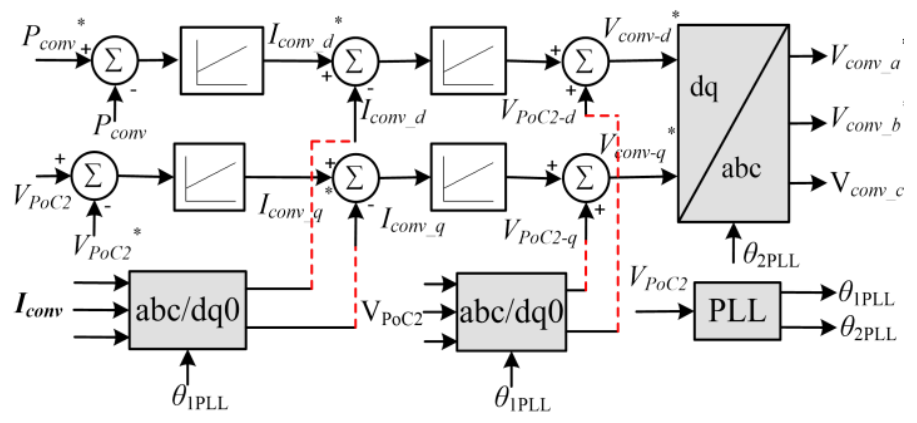

Fig. 2. Interface converter control structure ( $\theta_{2 \mathrm{PLL}}$ lags $\theta_{1 \mathrm{PLL}}$ by pi/6) 


\section{PROPOSED CONTROL STRATEGIES}

Two control strategies for the islanded operation of the ac-dc hybrid micro-grid are presented. The control strategies are explained and are then tested using a constant wind speed to focus on the islanding and grid reconnection transients. Control parameters are shown in Table 3 Appendix section.

\section{A. Method 1: Direct Frequency and Reactive Power Control}

\section{Control Scheme}

When the utility grid is disconnected, whether for intentional or forced islanding, the power balance is lost. This leads to variation in the microgrid ac voltage magnitude and frequency. Assuming that the microgrid was originally supplying power to the utility grid, the cage induction generator will speed up. Variation in the operating point also leads to a change in the reactive power requirements of the cage induction generator. Pitch control can be used to lower the extracted power but the dynamics of the assumed pitch controller are slow (time constant of 0.1s). In the islanded operation, the voltage magnitude can be maintained in the same way as for the utility grid connected operation, where the interface converter supplies the necessary reactive power to maintain the ac bus voltage (at $\left.P o C_{2}\right)$ at $1 \mathrm{pu}$. For the frequency regulation, a frequency control loop driving an active power reference, similar to [20] is proposed. The approach is similar to the typical microgrids secondary control [11] to drive the average frequency deviations to zero. For the case of the ac-dc hybrid microgrid, there is no need of a separate inverter as the scheme can exploit the interface converter, where the additional power transfer required $\left(\Delta P_{f}\right)$ for frequency regulation can be superimposed on the active power set point originally determined by the central controller to maintain power balance on the dc side. A schematic diagram of the proposed control is shown in Fig. 3. A frequency reference of $1.0 \mathrm{pu}$ is used in this work however the scheme can be easily adapted to introduce frequency droop. The ac bus frequency can be measured locally; else it can be estimated through knowledge of the induction generator rotational speed and instantaneous slip. The frequency loop is enabled once islanding operation is detected and will be disabled after re connection to the utility grid. Appropriate load shedding, dump loads or energy storage can be introduced on the dc sub grid to cater for the additional active power transfer. Also, the operating point of the PV system can be changed to aid maintaining the power balance. The central controller can then adjust the original power reference such that power balance is restored and the additional power request from the frequency loop drops to zero.

\section{Islanding detection}

The same frequency signal can be used for islanding detection. As mentioned before, the islanding event will lead to a change in the ac bus frequency. Appropriate thresholds can be set and the control is latched once the frequency goes out of the set range. The same signal can be used to open the sectionalizing switch in the case of utility grid failure. For this case, the frequency thresholds are set to $50 \pm 0.75 \mathrm{~Hz}$. The frequency loop is then disabled once the microgrid is reconnected to the utility grid. Appropriate logic can be used to reset the latch, as indicated in Fig. 3.

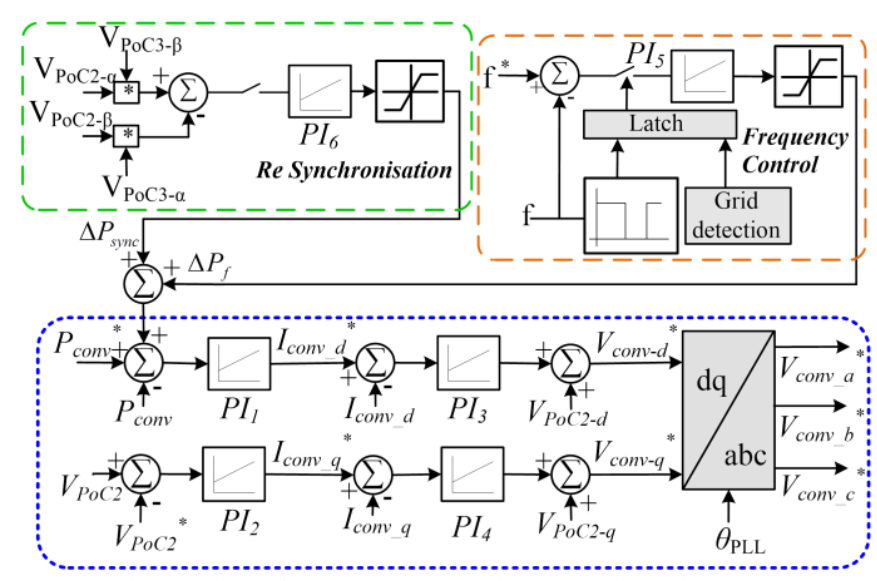

Fig. 3. Direct frequency and reactive power islanding control

\section{Re synchronization to the grid.}

Despite the voltage magnitude and frequency regulation, the micro-grid ac voltage will be phase shifted from the utility grid voltage. For utility grid reconnection, the control of the sectionalizing switch can detect instants when the two voltages are in phase to close the switch. However this may lead to a hard transition [8]. To soften the transition, an additional power component $\left(\Delta P_{\text {sync }}\right)$ is introduced to adjust the ac voltage phase in order to synchronize it with the utility grid before reconnection. The resynchronization process can be started once the utility grid becomes available following an islanding event. The phase error is detected in a similar way to the error driving the phase locked loop for the converter control, as shown in Fig. 3. There is no need for the controller to be fast since the micro-grid can continue operating in islanded mode till synchronization is obtained. In this work, the resynchronization control is enabled circa $2 \mathrm{~s}$ before utility grid connection.

In order to test the operation of the proposed scheme, the system was tested with a constant wind speed driving the cage induction generator. Plots for the frequency $(f)$, generator output power $\left(P_{I G}\right)$, grid power $\left(P_{\text {grid }}\right)$, interface converter power $\left(P_{c o n v}\right)$ and voltage levels $\left(V_{L a c}\right.$ and $\left.V_{P_{O C C}}\right)$ are shown in Fig. 4. The micro-grid was connected to the utility grid and operating in steady state till $10 \mathrm{~s}$. $2.35 \mathrm{MW}$ was being delivered to the utility grid while the central controller was requesting an active power transfer of $1.63 \mathrm{MW}$ from the ac bus to the dc bus. After 10s, the sectionalizing switch is opened such that the micro-grid becomes islanded. The frequency is seen to increase till the upper threshold is reached at which point the frequency loop is triggered. 


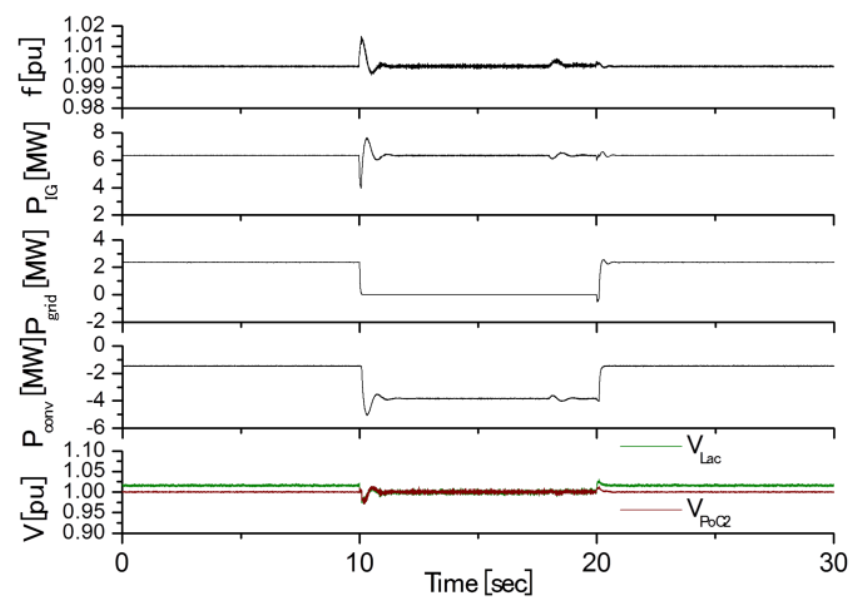

Fig. 4. Direct frequency and reactive power control operating with constant wind speed

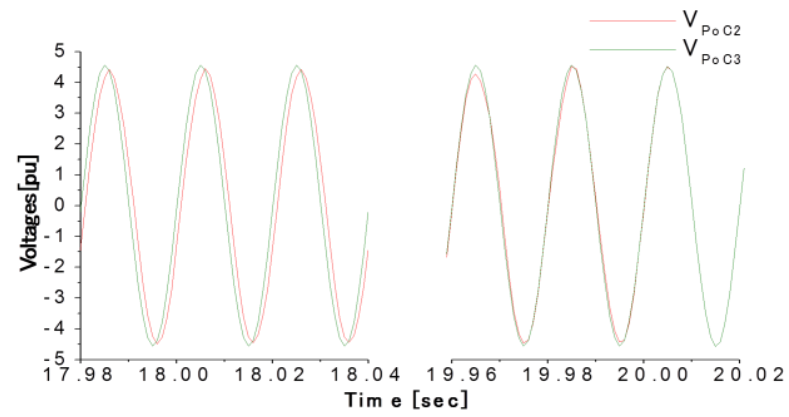

Fig. 5. Voltage resynchronization before grid reconnection

The converter power reference is thus adjusted so as to regulate the ac bus frequency and stabilize the induction generator. For this case, the additional power reference is kept through the islanded operation however this can be offset by an update of the central controller reference. The grid is assumed to become available at $18 \mathrm{~s}$, at which point the resynchronization controller is triggered. Its action can be seen on the converter active power reference. After the $\mathrm{PoC}_{2}$ and utility grid voltages are gradually brought in phase, as shown in Fig. 5, the sectionalizing switch is closed reconnecting the microgrid to the utility grid. At the same time the frequency loop is disabled. It can be seen from Fig. 4 that the islanding operation is successful and that the transition to utility grid reconnection is smooth.

\section{B. Method 2: Artificial grid}

\section{Control Scheme}

On disconnection of the utility grid, the microgrid loses the voltage magnitude and frequency references for the ac bus. Artificial references for the microgrid can be established through the creation of an artificial grid. This can be established by controlling a converter in voltage mode $[9,10]$ driven by voltage amplitude and frequency references. For this work, a battery energy storage system is introduced on the ac bus at $\mathrm{PoC}_{1}$ interfaced through a standard converter. This can be operated in PQ mode during grid connected operation to keep the battery charged and then in voltage mode during islanding operation. The one line diagram of the modified system is shown in Fig. 6. The artificial grid could also be connected at $\mathrm{PoC}_{2}$. It might then be sufficient to establish the artificial grid through the interface converter. It might also be the case that multiple interface converters are operated in parallel for increased reliability [29], in which case the control of one of them can be changed.

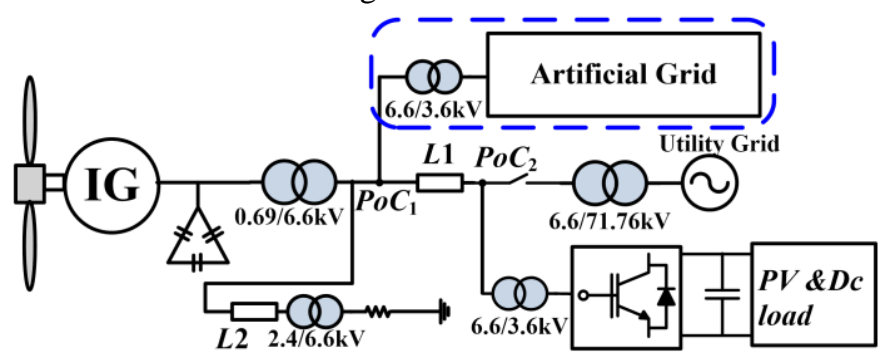

Fig. 6. Introduction of artificial grid

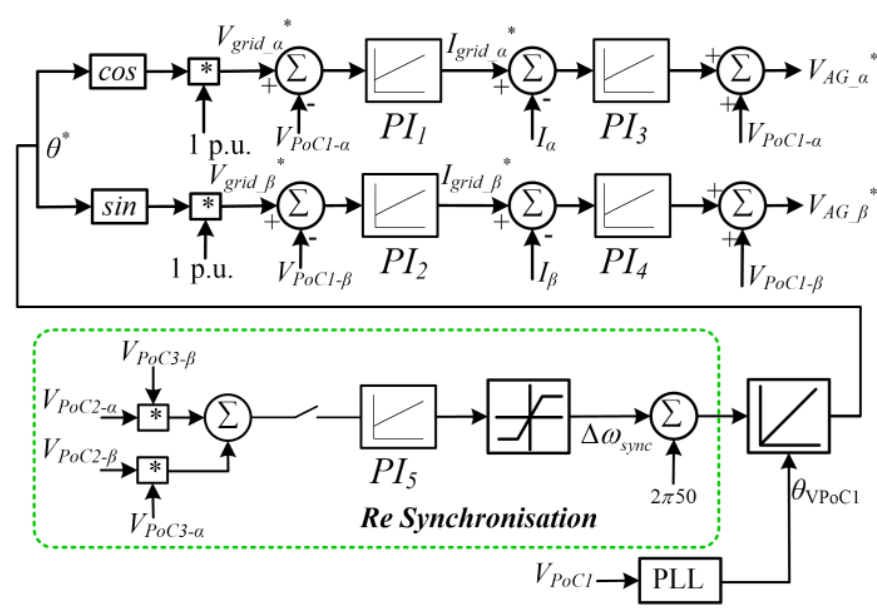

Fig. 7. Artificial grid islanding control

The voltage reference for the artificial grid is set to $1 \mathrm{pu}$ in this work however voltage droop can be easily introduced. The angle is obtained by integrating a constant $50 \mathrm{~Hz}$ reference. In order to preserve the voltage phase in the transition to islanded operation, the initial value of the integrator output is set from a phase locked loop tracking the $\mathrm{PoC}_{l}$ voltage. Once again, frequency droop can be easily introduced. Standard cascaded vector control implemented in the stationary $(\alpha \beta)$ frame, as shown in Fig. 7 , is used. A similar islanding detection scheme, as used for the frequency and reactive power based control, is used here.

\section{Re synchronization to the grid.}

For the same reasons as for the previous control scheme, the mircrogrid ac voltage at $\mathrm{PoC}_{2}$ is synchronized to the utility grid voltage before reconnection. The phase angle error is detected using the same structure as before. However the error drives a frequency reference $\left(\Delta \omega_{\text {sync }}\right)$ that is superimposed on the $50 \mathrm{~Hz}$ reference as shown in Fig. 7.

As for the previous control method, the system was tested with a constant wind speed driving the cage induction generator. Plots for the frequency $(f)$, generator output power 
$\left(P_{I G}\right)$, grid power $\left(P_{\text {grid }}\right)$, interface converter power $\left(P_{\text {conv }}\right)$ and voltage levels $\left(V_{L a c}\right.$ and $\left.V_{P o C 2}\right)$ are shown in Fig. 8. The microgrid was islanded at $10 \mathrm{~s}$. Due to the initial power transfer to the grid, the frequency increases till it reaches the threshold, at which point the artificial grid is triggered. It can be seen that the voltage levels and the frequency are regulated, while the interface converter active power reference remains constant for this case. The resynchronization is switched on at 18 s to bring the voltage gradually in phase, after which the static transfer switch can be closed. It can be seen from Fig. 8 that the islanding operation is successful and that the transition to utility grid reconnection is smooth also for this case.

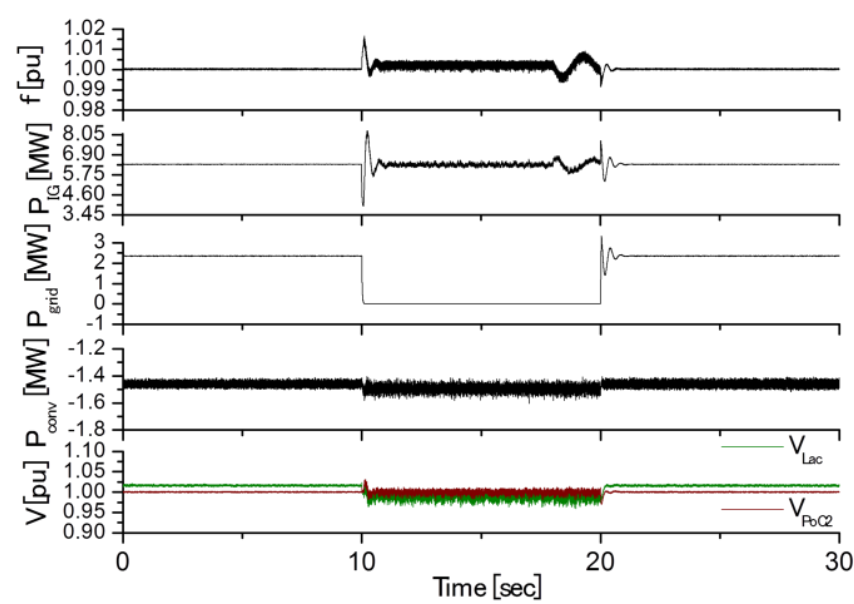

Fig. 8. Artificial grid control operating with constant wind speed

\section{RESULTS AND DISCUSSIONS}

This section presents simulation results of the two proposed control schemes for the islanding operation of the hybrid ac-dc micro-grid. During normal operation, the wind speed will not be constant and it will introduce another variation that has to be catered for. Real wind speed data, sampled at $3 \mathrm{~s}$ intervals, is used to drive the wind turbine for these simulations. It is opted here to overcome the variations in the wind driven generator output due to the varying wind speed by introducing a smoothing battery energy storage system (BESS) at $P o C_{l}$, as shown in Fig. 9.

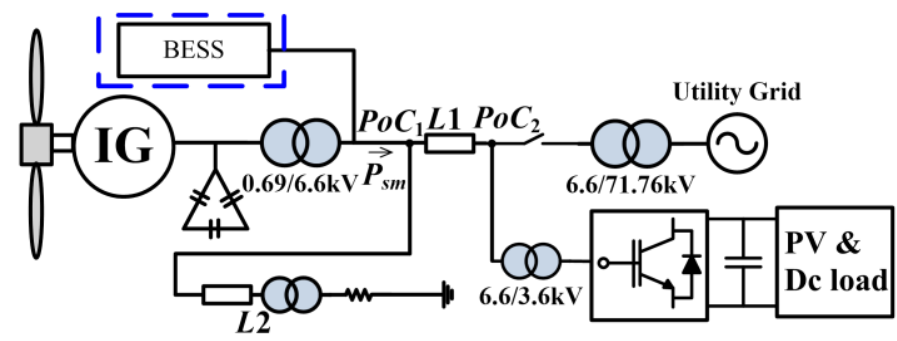

Fig. 9. Smoothing BESS introduced at the generator terminals

The BESS is controlled to smooth the output power to a constant reference value [30]. For both cases a reference of 4.34MW is used. It is not implied that this is the most cost effective solution and other solutions might be possible. However this solution allows the examination of the performance of the different elements of the micro-grid. All simulations are performed in PSCAD/EMTDC [31]. Simulation block sets for direct method is shown in Appendix.

\section{A.Method 1 - Direct Frequency and Reactive Power Control}

Figure 10 and 11 show the micro-grid operation using the proposed direct frequency and reactive control method when the cage induction generator based wind turbine is driven by real wind speed. The plots, from top to bottom, show the wind speed $\left(\mathrm{V}_{\mathrm{w}}\right)$, the frequency $(f)$, the generator output power $\left(P_{I G}\right)$, the smoothened output power $\left(P_{s m}\right)$, the grid power $\left(P_{\text {grid }}\right)$, the ac load $\left(L_{a c}\right)$, the interface converter power $\left(P_{\text {conv }}\right)$ and the voltage levels $\left(V_{L a c}\right.$ and $\left.V_{P O C 2}\right)$. The micro-grid is initially operating in steady state, exporting $0.50 \mathrm{MW}$ to the grid and $1.63 \mathrm{MW}$ to the dc bus.

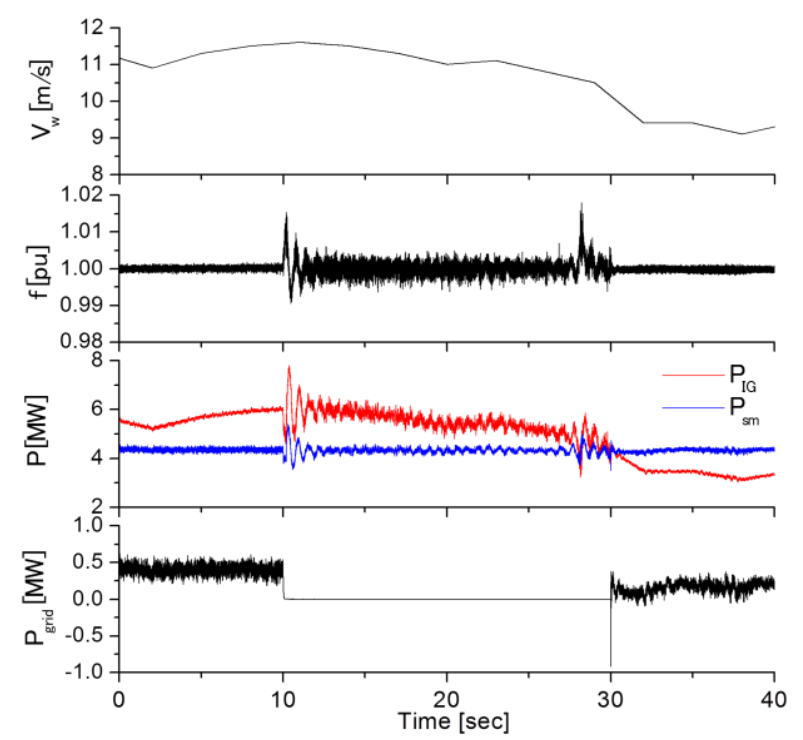

Fig. 10. Wind speed, frequency, generator and line power responses obtained using method-1 under variable wind speed

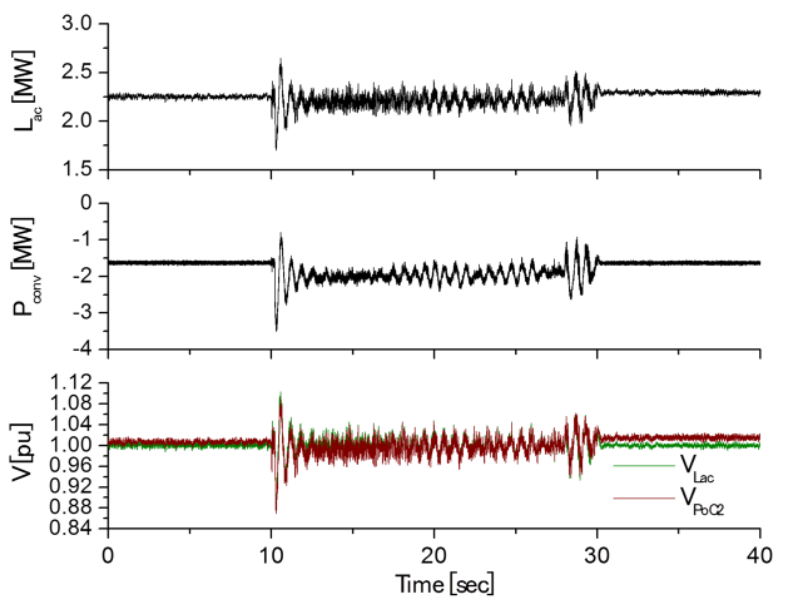

Fig. 11. Ac load power, converter power, and voltage responses obtained using method-1 under variable wind speed 
At 10 s, the utility grid is disconnected to initiate islanding operation. The resulting shift in frequency triggers the frequency control that directly modifies the interface converter reference. The voltage level is regulated as initially. It can be seen from Fig. 10 that the smoothened output power $\left(P_{s m}\right)$ does not follow the reference when the utility grid is lost. The frequency controller however is able to overcome the active power variation. Once the frequency is regulated, the smoothened power follows the reference value. Variations in the frequency can also be seen in the period from $28 \mathrm{~s}$ to $30 \mathrm{~s}$, when the resynchronization controller is enabled. The utility grid is reconnected at 30s. As for the case of the constant wind speed, a smooth transition is obtained.

\section{B.Method 2 - Artificial Grid}

The micro-grid operation under the same conditions as for the results shown in Fig. 10, 11, but using the artificial grid control scheme are shown in Fig. 12 and 13. The plots follow the same order as for Fig. 10 and 11. It can be observed that even in this case, the micro-grid operates successfully in islanded operation. The interface converter power flow $\left(P_{\text {conv }}\right)$ is smoother as a separate converter is used for the frequency regulation.

The frequency and voltage regulation obtained for the two proposed control schemes are compared in Fig. 14. The plots show the frequency $(f)$, the induction generator rotational speed $\left(\omega_{I G}\right)$ and the voltage level $\left(V_{P o C 2}\right)$. The frequency fluctuation for method 1 at resynchronization is $1.5 \%$ while for method 2 it is $1 \%$. The fluctuation for method 1 in rotational speed is $1.5 \%$ and fluctuation settles in $1 \mathrm{~s}$. In method 2, the fluctuation is $1.2 \%$, however it settles within 2 s.It can be seen that the behavior is very similar except for a more marked variation of in the rotational speed $\left(\omega_{I G}\right)$ during the resynchronization process of the artificial grid method. This should however be improved through retuning of the relevant controller.

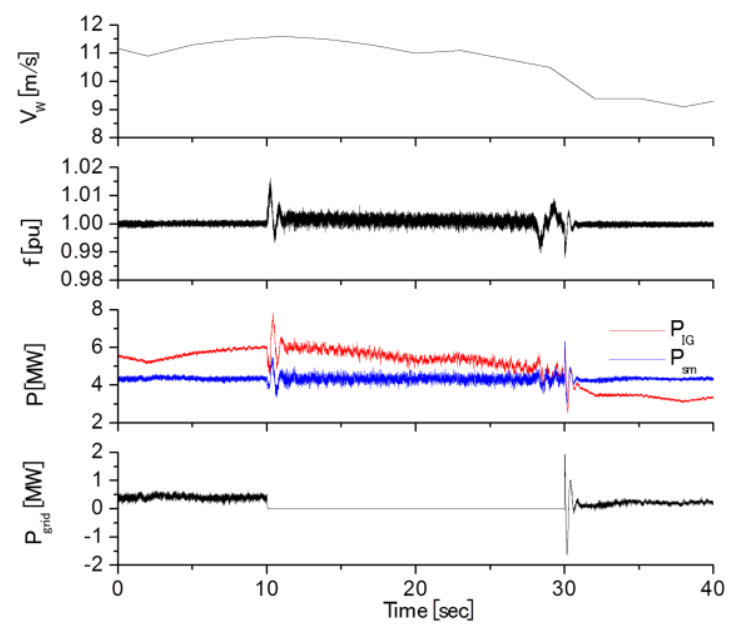

Fig. 12. Wind speed, frequency, generator and line power responses obtained using method-2 under variable wind speed

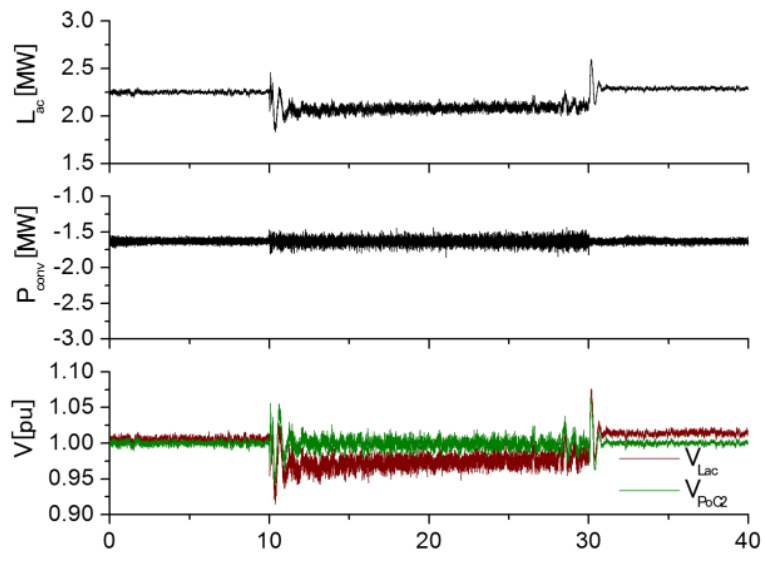

Fig. 13. Ac load power, converter power, and voltage responses obtained using method- 2 under variable wind speed

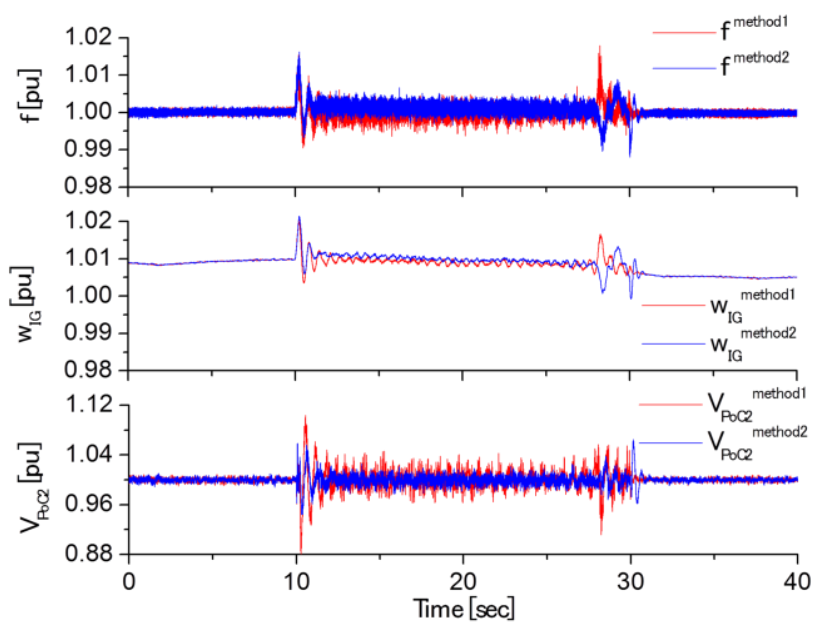

Fig. 14. Comparison of frequency and voltage regulation for the two proposed control schemes

\section{CONCLUSIONS}

This paper concerns the islanding operation of a hybrid dc-ac micro-grid with a high penetration of wind driven cage induction generators connected on the ac bus. Two control strategies, direct frequency and reactive power based control and the use of an artificial grid, were proposed to regulate the voltage and frequency during islanded operation. The former control scheme superimposes an additional power demand on the interface converter reference for the frequency regulation whilst maintaining the original voltage regulation loop. In the latter control scheme, an inverter is operated in voltage mode to provide artificial references for voltage amplitude and frequency. A battery storage system is introduced on the ac bus for this purpose in this work. However, as discussed, other options might be examined for example using one of the parallel converters used to interface the ac and dc buses. A voltage resynchronization scheme was also proposed for the two cases to bring the micro-grid voltage in phase with the utility grid voltage before reconnection.

Simulations in PSCAD/EMTDC have shown that both schemes can regulate the voltage and the frequency well when 
APPENDIX

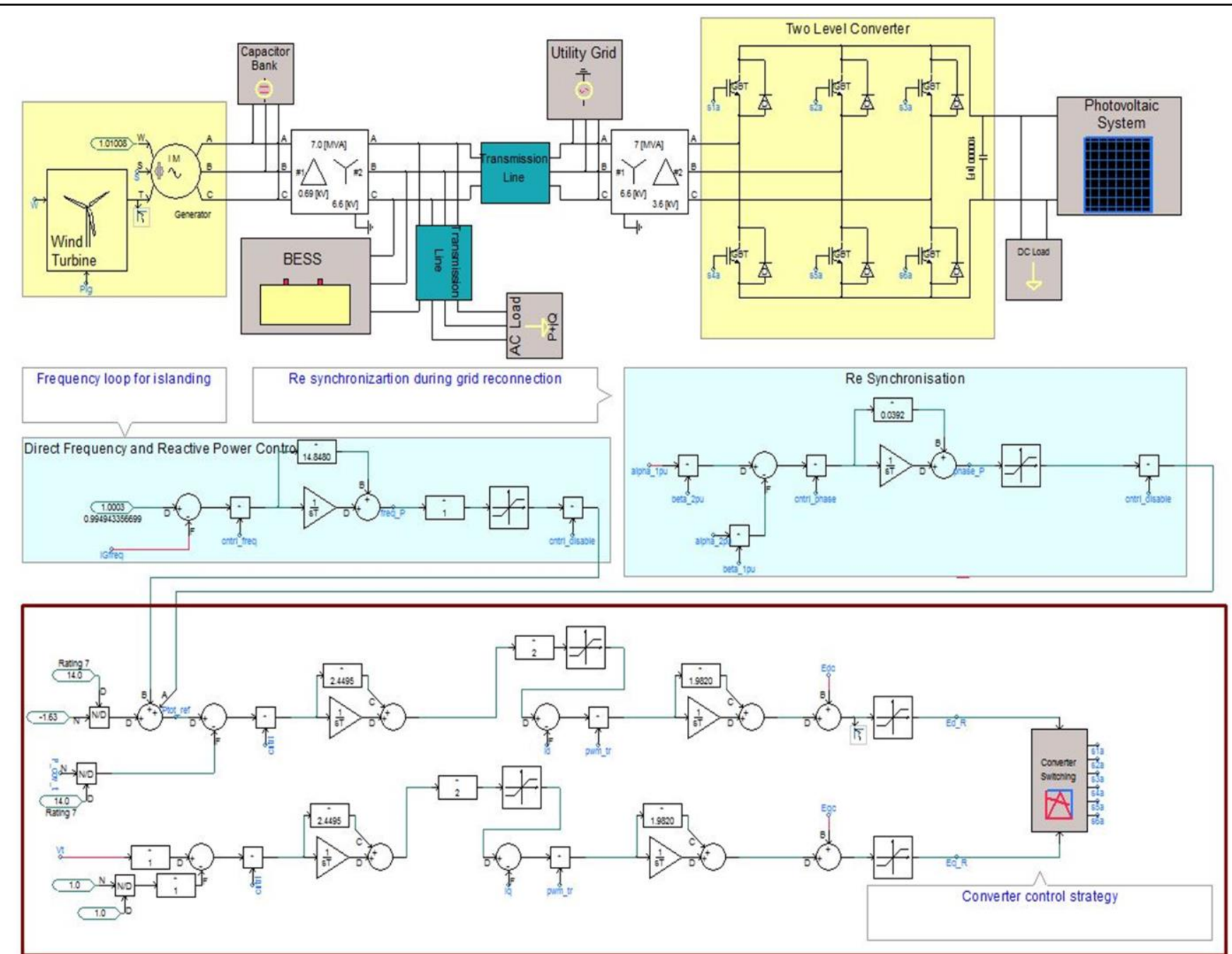

Fig. 15. Simplified simulation block set for direct approach

operating under a realistic scenario using real wind speed data and hence stabilize the operating point of the cage induction generator. Comparison of the performance of the two schemes shows that they can achieve comparable frequency and voltage regulation responses.

TABLE 1

INDUCTION GENERATOR PARAMETERS

\begin{tabular}{ll}
\hline \hline \multicolumn{1}{c}{ Type } & Quantity \\
\hline Rated voltage & $0.69 \mathrm{kV}$ \\
Power & $7 \mathrm{MVA}$ \\
Stator resistance & $0.01 \mathrm{pu}$ \\
Rotor resistance & $0.01 \mathrm{pu}$ \\
Leakage reactance & $0.1 \mathrm{pu}$ \\
Magnetizing reactance & $3.5 \mathrm{pu}$ \\
Rotor mutual reactance & $0.12 \mathrm{pu}$ \\
Inertia constant & $3 \mathrm{sec}$ \\
\hline \hline
\end{tabular}

TABLE 2

MICRO-GRID PARAMETERS

\begin{tabular}{ll}
\hline \hline \multicolumn{1}{c}{ Parameters } & Quantity \\
\hline Base MVA & $7 \mathrm{MVA}$ \\
Rated voltage & $6.6 \mathrm{kV}$ \\
DC generation & $0.5 \mathrm{MW}$ \\
AC load & $2.21 \mathrm{MW}, 2.4 \mathrm{kV}$ \\
DC load & $2.13 \mathrm{MW}, 6.6 \mathrm{kV}$ \\
DC bus voltage & $6.6 \mathrm{kV}$ \\
DC link capacitance & $100000 \mu \mathrm{F}$ \\
Converter Set point $\left(P_{\text {conv }}{ }^{*}\right)$ & $-1.63 \mathrm{MW}$ \\
PoC 2 voltage set point $\left(V_{P o C 2}{ }^{*}\right)$ & $1.0 \mathrm{pu}$ \\
Line impedance $\left(\mathrm{L}_{1}\right)$ & $0.01+\mathrm{j} 0.035 \mathrm{pu}$ \\
Line impedance $\left(\mathrm{L}_{2}\right)$ & $0.001+\mathrm{j} 0.002 \mathrm{pu}$ \\
\hline \hline
\end{tabular}


TABLE 3

CONTROL SETTING PARAMETERS

\begin{tabular}{|c|c|c|c|}
\hline Method & PI controller & Gain (KP) & $\begin{array}{c}\text { Time constant } \\
\text { (Ti) }\end{array}$ \\
\hline \multirow{6}{*}{$\begin{array}{l}\bar{Z} \\
\overline{0} \\
\text { 惫 }\end{array}$} & PI1 & 3 & $0.012 \mathrm{~s}$ \\
\hline & PI2 & 3 & $0.012 \mathrm{~s}$ \\
\hline & PI3 & 1.3 & $0.0116 \mathrm{~s}$ \\
\hline & PI4 & 1.3 & $0.0116 \mathrm{~s}$ \\
\hline & PI5 & 10 & $0.01 \mathrm{~s}$ \\
\hline & PI6 & 0.03 & $1 \mathrm{~s}$ \\
\hline \multirow{5}{*}{ 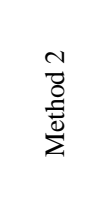 } & PI1 & 5 & $0.0012 \mathrm{~s}$ \\
\hline & $\mathrm{PI} 2$ & 5 & $0.0012 \mathrm{~s}$ \\
\hline & $\mathrm{PI} 3$ & 5 & $0.0011 \mathrm{~s}$ \\
\hline & $\mathrm{PI} 4$ & 5 & $0.0011 \mathrm{~s}$ \\
\hline & PI5 & 0.577 & $0.075 \mathrm{~s}$ \\
\hline
\end{tabular}

\section{NOMENCLATURE}

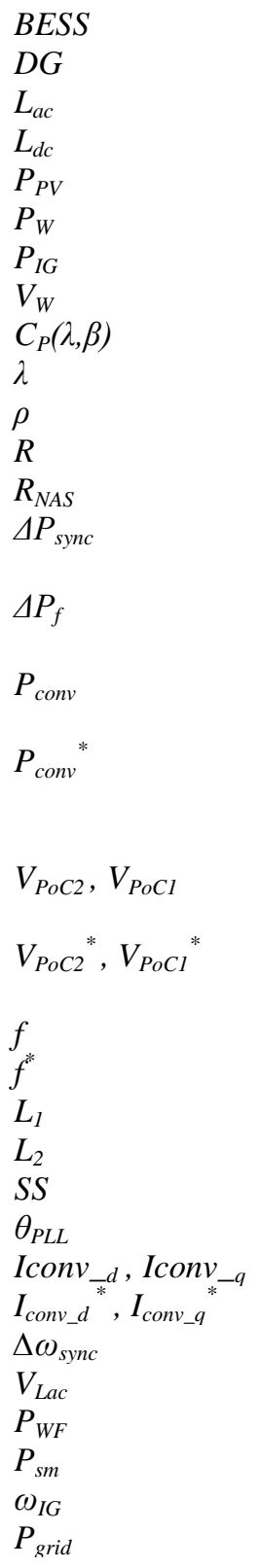

Battery Energy Storage System

Distributed Generation Systems

AC load consumption

DC load consumption

Photovoltaic cell output power

Wind turbine extracted power

Generator output power

Wind speed

Power co-efficient

Tip speed ratio

Air density

Radius of the turbine

Battery internal resistance

Adjusted set power from re-

synchronization block

Adjusted set power from secondary

frequency control block

Power transfer through interlinking

converter between AC \& DC buses

Reference power transfer through

interlinking converter between AC \& DC

buses

Voltage measured at point $\mathrm{PoC} 2$ and

PoC1

Reference voltage at point $\mathrm{PoC} 2$ and

$\mathrm{PoC} 1$

Measured system frequency

Reference for system frequency

Medium length line

Short length line

Sectionalizing switch

PLL angle

$\mathrm{d}$-axis and q-axis current

$\mathrm{d}$-axis and q-axis reference current

Frequency reference

Voltage at ac load

Output power of wind farm

Smoothen output power

Rotational speed

Power export or imported by grid

\section{ACKNOWLEDGMENT}

The authors would like to gratefully acknowledge the support of The Petroleum Institute Research Center in Abu Dhabi, UAE for funding this research. Thanks are also due to Kitami Institute of Technology, Japan for providing the real wind speed data.

\section{REFERENCES}

[1] M.A. Abdullah, A.P. Agalgaonkar, K.M. Muttaqi, "Assessment of energy supply and continuity of service in distribution network with renewable distributed generation," Appl Energy, Vol. 113, pp. 10151026, January 2014

[2] C. L. Smallwood, "Distributed generation in autonomous and nonautonomous micro grids," in Proc. Rural Electric Power Conf., 2002, pp. D1-D1-6.

[3] J.Y. Kim. J.H. jeon, S.K. Kim, C. Cho, J.H. Park, H.M. Kim and K.Y. Nam, "Cooperative control strategy for energy storage system and microsources for stabilizing the microgrid during islanded operation," IEEE Trans. on Power Elecs., Vol. 25, No. 12, Dec 2010.

[4] Xiandong Ma, Yifei Wang, Jianrong Qin, "Generic model of a community-based microgrid integrating wind turbines, photovoltaics and CHP generations", Appl Energy, Vol. 112, pp. 1475-1482, December 2013.

[5] S. Barsali, M. Ceraolo, P. Pelacchi and D. Poli, "Control techniques of dispersed generators to improve the continuity of electricity supply", in Power Engineering Society Winter Meeting, 2002. IEEE, Vol. 2. IEEE, 2002.

[6] K. De Brabandere, K. Vanthournout, J. Driesen, G. Deconinck and R. Belmans, "Control of Microgrids", in Power Engineering Society General Meeting, 2007, IEEE, Jun. 2007, pp. 1-7.

[7] Siamak Naderi, Edris Pouresmaeil, Wenzhong David Gao, "The frequency-independent control method for distributed generation systems", Appl Energy, Vol. 96, pp. 272-280, August 2012.

[8] I.J. Balaguer, Q. Lei, S. Yang, U. Supatti and F.Z. Peng, "Control for grid-connected and international islanding operations of distributed power generation", IEEE Trans. Industrial Elecs., vol. 58, no. 1, Jan. 2011.

[9] J.M. Guerrero, L. Hang and J. Uceda, "Control of distributed uninterruptible power supply systems", IEEE Trans. Industrial Elecs., vol. 55, no. 8, Aug 2008.

[10] J.A. Pecas Lopes, C.L. Moreira and A.G. Madureira, "Defining control strategies for microgrids islanded operation", IEEE Trans. Power Sys., vol. 21, No. 2, pp. 916-924, May 2006.

[11] A. Madureira, C. Moreira and J.A. Pecas Lopes, "Secondary loadfrequency control for microgrids in islanded operation", in Proc. International Conference on Renewable Energy and Power Quality ICREPQ ‘05, Spain. 2005.

[12] J.M. Guerrero, "Advanced control architectures for intelligent microgrids-PartI: Decentralized and Hierarchical control," IEEE Trans. Ind. Electronics, vol. 60, No. 4, pp. 1254-1262, Apr 2013.

[13] M.C. Chandorkar and D.M. Divan, "Decentralized operation of distributed UPS systems", in Power Electronics, Drives and Energy Systems for Industrial Growth, 1996, Proceedings of the 1996 International conference, vol. 1, pp. 565-571, Jan. 1996.

[14] The Global Wind Energy Council, Global Wind Report, Annual market update 2010. Available: http://www.gwec.net/

[15] N. K. Ardeshna and B. H. Chowdhury, "Optimizing Micro-grid Operations in the Presence of Wind Generation," Power Symposium, NAPS'08, 28-30 Sept. 2008.

[16] G. Dastagir, and L. Lopes, "Voltage and frequency regulation of a standalone self-excited induction generator", in IEEE Canada Electrical Power Conference, 2007.

[17] R. Ahshan, M.T. Iqbal, George K.I. Mann, "Controller for a small induction-generator based wind-turbine", Appl Energy, Vol. 85, Issue 4, pp. 218-227, April 2008.

[18] A.A. Shaltout, A.F. El-Ramahi, "Maximum power tracking for a wind driven induction generator connected to a utility network," Appl Energy, Vol. 52, Issues 2-3, pp. 243-253, 1995.

[19] S.M. Muyeen, M.H. Ali, R. Takahashi, T. Murata, Y. Tomaki, A. Sakahara and E. Sasano, "Comparative study on transient stability 
analysios of wind turbine generator system using different drive train models," IET Renew. Power Gener., vol. 2, no. 2, pp. 131-141, 2007.

[20] L. Lopes and R. Almeida, "Wind-driven self-excited induction generator with voltage and frequency regulated by a reduced-rating voltage source inverter," IEEE Trans. Energy Conv., vol. 21, no. 2, Jun 2006.

[21] N.Eghtedarpour and E. Farjah, "Power control and management in a hybrid AC/DC microgrid," IEEE Trans. on Smart Grid, vol. 5, no. 3, (2014)

[22] R. Majumder, "A hybrid microgrid with DC connection at back to back converters," IEEE Trans. on Smart Grid, vol. 5, no. 1, (2014).

[23] S.P. Singh, B. Singh, and M.P. Jain, "Performance characteristics and optimum utilization of a cage machine as capacitor excited induction generator," IEEE Trans. Energy Conv., vol. 5, no. 4, Dec 1990.

[24] J. Bjornstedt, "Island operation with induction generators: Frequency and voltage control," Licentiate Thesis, Dept. of Measurement Technology and Industrial Electrical Engineering, Lund University, 2009.

[25] Wasynczuk, O., D. T. Man, and J. P. Sullivan. "Dynamic Behavior of a Class of Wind Turbine Generators During Randon Wind Fluctuations." IEEE Trans. on Power Apparatus and Systems, Vol. PAS100, No, 6, pp. 2837-2845, 1981.

[26] X. Liu, P. Wang and P. Loh, "A hybrid ac/dc micro-grid,", in IPEC, 2010 Conference Proceedigns, pp. 746-751, Oct. 2010.

[27] P. Wang, X. Liu, C. Jin, P. Loh and F. Choo, "A hybrid ac/dc mirco-grid architecture, operation and control," in Power and Energy Society General Meeting, 2011 IEEE, pp. 1-8, Jul. 2011.

[28] L. Xu, and D. Chen, "Control and Operation of a DC Microgrid With Variable Generation and Energy Storage," IEEE Trans. Power Delivery, vol. 26, No. 4, pp. 2513-2522, Oct 2011.

[29] M. N. Ambia, A. Al-Durra, S.M. Muyeen, "Centralized Power Control Strategy for AC-DC Hybrid Micro-grid System using Multi-converter Scheme," in Proc. IECON 2011- 37th Annual Conference on IEEE Industrial Electronics Society, Melbourne, Australia, Nov. 7-10, 2011, pp. 843-848.

[30] S.M. Muyeen, M.H. Ali, R. Takahashi, T. Murata, and J. Tamura, "Wind generator output power smoothing and terminal voltage regulation by using STACOM/BESS", in Power Tech, 2007 IEEE Lausanne, pp.12321237, Jul. 2007.

[31] “PSCAD/EMTDC Manual,” Manitoba HVDC Research Center, 1994. 